\title{
TEKNIK MENENTUKAN WAKTU HILANGNYA SYAFA $Q$ (CAHAYA MERAH) MENGGUNAKAN SKY QUALITY METER (SQM) DENGAN METODE TITIK POTONG (CUTOFF)
}

\author{
M. Asep Rizkiawan*, Rosalina, Emilia Roza
}

Fakultas Teknik Universitas Muhammadiyah Prof. DR. HAMKA

e-mail*: aseprizkiawan10@gmail.com

\begin{tabular}{|l|l|r|r|} 
Diterima 28 Juni 2021 & Direvisi 31 Juli 2021 & Disetujui 6 Agustus 2021 & Dipublikasikan 30 Agustus 2021 \\
\hline
\end{tabular}

https://doi.org/10.33369/jkf.4.2.103-111

\begin{abstract}
ABSTRAK
Dalam penelitian ini akan diukur tingkat kecerahan langit untuk mengetahui waktu hilangnya syafaq (cahaya mega merah) yang ada dilangit pada waktu malam hari. Imam Syafi'I dan mayoritas ulama berpendapat bahwa awal waktu Isya' ialah Ketika hilangnya mega merah, sedangkan Imam Hanafi berpendapat bahwa awal waktu Isya' ialah Ketika munculnya mega hitam atau disaat langit benar benar gelap, artinya langit benar-benar dalam keadaan gelap. Dalam melakukan pengukuran tingkat kecerahan langit peneliti menggunakan teknologi sensor non image yaitu Sky Quality Meter (SQM). Sky Quality Meter (SQM) merupakan alat untuk mengukur tingkat kecerahan langit. Pengukuran dilakukan dengan menggunakan fotometer portabel, ringan, dan relative murah dengan koneksi USB yaitu Unihedron Sky Quality Meter (SQM). Metode pengolahan data menggunakan MATLAB dan Microsoft office excel untuk menampilkan grafik dan melakukan pendekatan persamaan polynomial 5. Data percobaan diperoleh dari perekaman oleh sky Quality meter (SQM). Hasil penelitian dalam data yang telah diolah dan diproses menunjukan bahwa waktu hilangnya syafaq (cahaya mega merah) paling awal muncul pada pukul 18:29:33 WIB dan paling terakhir muncul pada pukul 18:51:54 WIB. Dapat disimpulkan bahwa waktu hilangnya syafaq (cahaya mega merah) itu tidak pasti waktunya atau tidak menentu dalam tiap harinya, tapi dalam penelitian ini dapat diketahui bahwa hilangnya syafaq (cahaya mega merah) berdasarkan data yang diperolah serta diproses menggunakan microsoft office excel dan matlab menunjukan range waktu yaitu pukul 18:29:33 sampai 18:51.54
\end{abstract}

Kata kunci : MATLAB, Microsoft office excel, Sky Quality Meter (SQM), waktu syafaq

\begin{abstract}
In this study, the brightness of the sky will be measured to determine the time of loss of syafaq (red light) in the sky at night. Imam Syafi'i and the majority of scholars are of the opinion that the beginning of Isha' is when the red mega disappears, while Imam Hanafi is of the opinion that the beginning of Isha' is when the black mega appears or when the sky is really dark, meaning that the sky is really dark. In measuring the brightness of the sky, the researchers used nonimage sensor technology, namely Sky Quality Meter (SQM). Sky Quality Meter (SQM) is a tool to measure the brightness of the sky. Measurements were carried out using a portable, lightweight, and relatively inexpensive photometer with a USB connection, namely the Unihedron Sky Quality Meter (SQM). The data processing method uses MATLAB and Microsoft office excel to display graphs and approach polynomial 5 equations. Experimental data is obtained from recording by sky Quality meter (SQM). The results of the study in data that have been processed and processed show that the time of the disappearance of the syafaq (mega red light) appears the earliest at 18:29:33 WIB and the last time appears at 18:51:54 WIB. It can be concluded that the time of the disappearance of syafaq (mega red light) is uncertain or erratic in each day, but in this study it can be seen that the loss of syafaq (mega red light) based on data obtained and processed using Microsoft Office Excel and Matlab shows a range time is 18:29:33 to 18:51.54.
\end{abstract}

Keywords: MATLAB, Microsoft office excel, Sky Quality Meter (SQM), Syafaq time.

\section{PENDAHULUAN}

Secara astronomis, kita dapat menghitung posisi matahari di lokasi kritis tertentu, dengan akurasi yang relatif baik. Saat matahari terbit, saat matahari berada pada titik kulminasinya, posisi tersebut adalah saat matahari terbenam. Namun, untuk shalat subuh dan isya', masalahnya tidak langsung karena bola bumi telah mengunci matahari yang telah terbenam. Oleh karena itu, telah 
berada di belahan bumi yang berbeda dari tempat kita berada (1). Kecerahan langit pada malam hari dengan nilai kelembaban dan suhu bergantung pada waktu, dengan kelembaban memiliki fungsi penting terhadap kecerahan langit malam. Oleh karena itu, perubahan kualitas langit akan seiring dengan perubahan kelembaban (2).

Penentuan awal waktu salat merupakan hal yang sangat essential bagi umat muslim karena berkaitan dengan syarat sahnya, Shalat tidak dikerjakan kapanpun sesuai dengan kemauan kita melainkan terdapat penentuan awal waktu dan akhir waktu shalat sebagai pedoman umat muslim untuk melakukannya (3). Penentuan secara akurat waktu salat zuhur, asar dan magrib tidak terlalu sulit dikarenakan pergerakan matahari dapat diukur dengan panjang bayangan yang terlihat jelas. Namun, ada beberapa kesulitan dalam penentuan yang tepat untuk waktu salat subuh dan isya karena matahari berada dibawah horizon. Sehingga pengukuran bayangan tidak bisa ditampilkan (4). SQM merupakan alat buatan dari UNIHEDRON yang berukuran saku, SQM menunjukan hasil dengan satuan MPSAS (mag/arcsec2), yang perekamanya dapat dilakukan tiap waktu (5).

Semakin matahari berada jauh dibawah horizon, maka perubahan TKL tidak signifikan. Pengukuran TKL membutuhkan sensor cahaya yang sensitif, salah satunya dengan menggunakan SQM. Pengukuran kecerahan langit dengan menggunakan SQM menunjukan bahwa semakin gelap langit dan semakin banyak bermunculan bintang maka nilainya akan semakin besar (6). Pada penelitian ini dijelaskan mengenai pengukuran akurasi dalam penentuan waktu awal mulai masuknya solat isya. Laporan ini menyajikan hasil pengukuran kecerahan langit untuk hari tertentu yang dipilih dengan kriteria yang ditentukan, yaitu cuaca cerah, minimal awan, dan tidak ada sabit bulan. Pengukuran kecerahan langit dilakukan di lokasi FKIP UHAMKA, dengan titik kordinat longitude -6.303291 dan latitude 106.872089. Atmosfer memiliki peran lain dalam merefleksikan cahaya, misalnya cahaya buatan hasil dari aktivitas manusia yang dipantulkan atmosfer

Penelitian penentuan waktu awal mulai masuknya solat isya didasari oleh keingintahuan serta menentukan waktu awal masuknya dengan perhitungan data. Karena dalam hadits menyebutkan bahwa awal masuknya solat isya adalah Ketika syafaq (cahaya mega merah) yang ada dilangit pada waktu malam hari telah menghilang. Imam Syafi'I dan mayoritas ulama berpendapat bahwa awal waktu Isya' ialah Ketika hilangnya mega merah, sedangkan Imam Hanafi berpendapat bahwa awal waktu Isya' ialah Ketika munculnya mega hitam atau disaat langit benar benar gelap, artinya langit benar-benar dalam keadaan gelap (7). Awal waktu Isya' adalah Ketika mega merah telah terbenam sampai tengah malam yang pertengahan. Dalam astronomi mega merah disebut dengan bias partikel. Pada teknologi modern ini terdapat alat yang berfungsi untuk mengukur tingkat kecerahan langit yaitu Sky Quality Meter (SQM). Data ketinggian tempat dan kecemerlangan langit selama ini masih terabaikan dalam proses mencari ketinggian matahari untuk patokan awal waktu salat, padahal secara geografis negara Indonesia sangat luas secara lintang dan panjang secara bujur (8). Polusi cahaya dapat didefinisikan sebagai situasi ketika organisme terpapar cahaya di tempat yang salah, pada waktu yang salah atau pada intensitas yang salah, hasil yang tidak diinginkan dari penerangan listrik, atau lampu buatan yang berlebihan dan mencolok disebabkan oleh desain pencahayaan yang buruk (9).

Pengukuran menggunakan Sky Quality Meter (SQM) dengan berdasarkan tingkat kecerahan langit. Penelitian ini dilengkapi dengan data-data yang telah diambil, data-data berupa gambar grafik, data angka yang telah diolah menggunakan Microsoft excel dan software Matlab. Pengambilan data menggunakan alat Sky Quality Meter (SQM). Proses atau teknis dari pengambilan data ini yaitu dengan mengukur kecerahan langit. Pengukuran dilakukan dengan menggunakan fotometer portabel, ringan, dan relative murah dengan koneksi USB yaitu Unihedron Sky Quality Meter (SQM). Waktu salat Subuh berbeda dengan waktu salat Zuhur, Asar dan Maghrib yang dapat ditentukan secara akurat dengan melihat panjang bayangan benda. Nilai sudut matahari yang terlihat dari cahaya senja berdasarkan pengamatan menggunakan Sky Quality Meter (SQM) menunjukkan cahayanya fluktuatif dan tidak konstan (10).

Waktu salat Subuh dan Isya tidak dapat ditentukan dengan melihat bayangan benda karena Matahari berada di bawah horizon. Fajar sadik dapat dilihat secara langsung atau dapat ditentukan dengan mengukur perubahan kecerahan langit yang disebabkan pembiasan

Teknik Menentukan Waktu Hilangnya Syafaq (Cahaya Merah) Menggunakan Sky Quality Meter (SQM) dengan Metode....

M. Asep Rizkiawan, Rosalina, Emilia Roza 
cahaya Matahari menggunakan SQM (11). Dengan ini peneliti mengambil judul Teknik menentukan waktu hilangnya syafaq (cahaya mega merah) menggunakan sky quality meter (SQM) dengan metode titik potong (cutoff) bertujuan untuk mengetahui proses pengambilan data menggunakan sky quality meter (SQM) dan mendapatkan titik pototng guna mengetahui waktu hilangnya syafaq (cahaya merah) melalui pemrosesan pada Microsoft office excel dan MATLAB.

\section{METODE PENELITIAN}

Metode Penelitian ini yaitu observasi terjun langsung ke lapangan, Pengambilan data dilakukan dengan kondisi dan cuaca yang baik, bebas dari mendung dan hujan atau cuaca buruk. Pengambilan Data dilakukan di FKIP UHAMKA, Kampung Rambutan, Ciracas, Jakarta Timur, Jakarta, Indonesia dengan titik kordinat longitude -6.303291 dan latitude 106.872089 pada pukul 18:10 sampai dengan 19:10 WIB. Ada 12 data yang dihimpun yang berrarti ada 12 hari untuk pengambilan datanya.

Tabel 1. Frekuensi pengambilan data

\begin{tabular}{ccccc}
\hline No & Hari & Tanggal & Bulan & Tahun \\
\hline 1 & Senin & 29 & Maret & 2021 \\
2 & Kamis & 1 & April & 2021 \\
3 & Jum'at & 2 & April & 2021 \\
4 & Sabtu & 3 & April & 2021 \\
5 & Minggu & 4 & April & 2021 \\
6 & Selasa & 6 & April & 2021 \\
7 & Rabu & 7 & April & 2021 \\
8 & Kamis & 8 & April & 2021 \\
9 & Jum'at & 9 & April & 2021 \\
10 & Rabu & 21 & April & 2021 \\
11 & Kamis & 22 & April & 2021 \\
12 & Sabtu & 24 & April & 2021 \\
\hline
\end{tabular}

Proses atau teknis dari pengambilan data ini yaitu dengan mengukur kecerahan langit. Pengukuran dilakukan dengan menggunakan fotometer portabel, ringan, dan relative murah dengan koneksi USB yaitu unihedron sky quality Meter (SQM). Resolusi temporal pengambilan data dilakukan setiap detik (12). Rentang interval waktu dalam penelitian ini diterapkan 15 detik. Dengan satu kali pengambilan data didapat 270 data. Dengan sudut kemiringan Sky Quality Meter $(\mathrm{SQM}) \pm 65$ derajat terhadap langit. Sky Quality Meter (SQM) alat untuk mengukur kecerahan langit malam(1). Microsoft office excel Sebuah program aplikasi lembar kerja spreadsheet yang dibuat dan didstribusikan oleh Microsoft corporation untuk sistem operasi Microsoft windows dan mac OS. Aplikasi ini memiliki fitur kalkulasi dan pembuatan grafik yang berupa pengolah angka (13). MATLAB (Matrix Laboratory) merupakan suatu program untuk komputasi numerik, analisis dan merupakan suatu pemrograman matematika lanjutan yang dibentuk dengan dasar pemikiran menggunakan sifat dan bentuk matriks (14). Matlab Tidak diperlukan penulisan program khusus untuk operasi-operasi matriks seperti perkalian matriks atau invers matriks. Oleh karena itu bahasa MATLAB menyelesaikan masalah tersebut memerlukan waktu lebih cepat dibanding waktu yang dibutuhkan bahasa pemrograman tingkat tinggi lain (15).

Tabel 2. Spesifikasi Sky Quality Meter (SQM) (16)

\section{SQM LU-DL}

\section{Ukuran SQM \\ Berat SQM : \\ Berat/Panjang kabel USB : \\ Kapasitas penyimpanan data logger :}

Akurasi waktu :

\subsection{Alur Pelaksanaan Kerja}

Pada tahap ini merupakan tahap alur pelaksanaan kerja yang dimana peneliti dalam menjalankan kerja seperti dengan flowchart dibawah ini, agar pelaksanaan kerja berjalan dengan

\section{$5,5 " \times 2,6 " \times 1,1 "$ 110 gram \\ $140 \mathrm{gram} / 3$ meter}

1 MB Flash, 32 bytes per record $=32768$ data records total

Real Time Clock (RTC) 
baik sesuai dengan yang diinginkan. Alur pelaksanaan kerja pada awal yaitu adalah memulai yaitu adalah awal untuk melaksanakan kerja, lalu kemudian ke tahap selanjutnya yaitu mempersiapkan alat yang diperlukan dalam pelaksanaan kerja ataupun pelaksanaan penelitian, pada tahap selanjutnya adalah tahap pengolahan data SQM, artinya data yang sudah diperoleh dari SQM kemudian diproses, setelah data diproses tahap selanjutnya adalah menentukan titik potong (Cutoff) pada data yang sudah diolah.

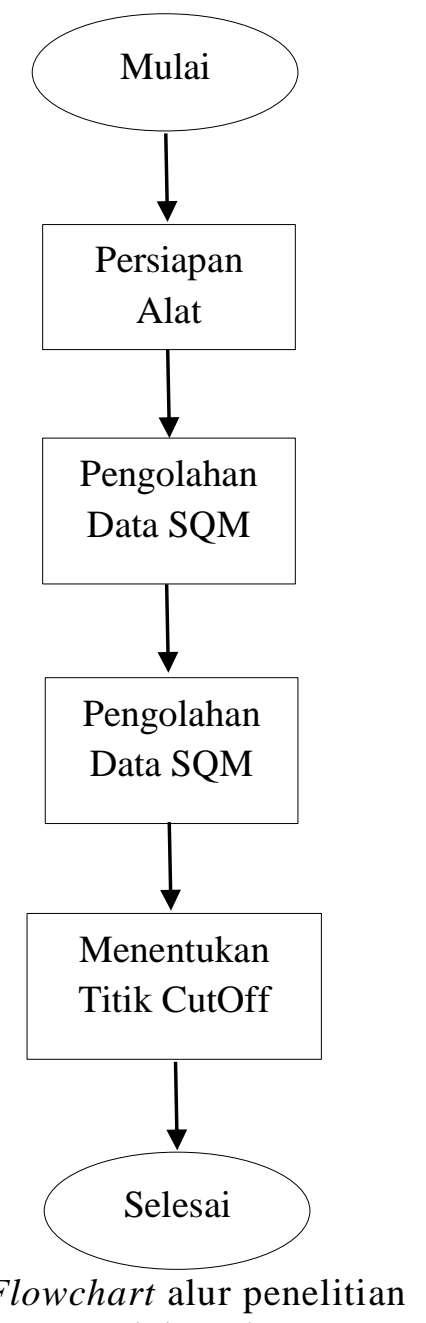

2. 2 Tahapan Teknis dalam pengambilan dan pengolahan data

Tahapan teknis dalam melaksanakan atau melakukan pengambilan data serta pengolahan data dalam penelitian ini adalah sebagai berikut: 1) mempersiapkan alat dan aplikasi yang digunakan untuk pengambilan data, yaitu: Tripod, Laptop, Sky Quality Meter (SQM), Aplikasi Unihedron Device Manager (UDM); 2) pengambilan data menggunakan Sky Quality Meter (SQM) yang dihubungkan ke laptop dan diaplikasikan menggunakan software Unihedron Device Manager (UDM), data yang diambil berupa grafik dilakukan secara kontinyu selama 15 detik sekali; 3) waktu pengambilan data ba'da maghrib pukul 18.10 sampai dengan pukul 19.10 WIB; 4) setelah pengambilan data selesai dilakukan, kemudian data di simpan pada software Unihedron Device Manager (UDM); 5) hasil data yang disimpan di software Unihedron Device Manager (UDM), kemudian di pindahkan ke dalam Microsoft office word; 6) data dari Microsoft office word kemudian diseleksi di microsoft office excel data mana saja yang diperlukan yaitu nomor, local, date \& time. Ax; 7) data kemudian diubah menjadi grafik dalam microsoft office excel dengan pendeketan polynomial $5 ; 8)$ selanjutnya data diproses dengan pendekatan polynomial 5 menggunakan aplikasi Matlab; 9) memberikan program input number dan input matriks di dalam software matlab, agar dapat memasukkan banyaknya data agar diproses pada matlab; 10) setelah didapatkan hasilnya maka dipindahkan kedalam Microsoft office excel; dan 11) data nomor, time. Ax diplot grafik pada Microsoft office excel dan dilihat diwaktu berapakah titik potong grafik tersebut, maka itulah waktu hilangnya syafaq (cahaya mega merah). 


\section{3 Pengambilan dan Perekaman Data}

Tahapan-tahapan dalam melakukan pengambilan dan perekaman data adalah (1) hubungkan sky quality meter (SQM) dengan komputer menggunakan kabel USB; (2) software unihedron device manager (UDM), klik find, pilih tab data logging, kemudian pilih dan klik log continuous; (3) untuk mendapatkan rekam data yang sudah dilakukan, klik Retrieve, muncul dialog DL Retrieve dan klik Retrieve All, maka seluruh data yang telah terekam akan dimunculkan, kemudian simpan. Rekam data SQM otomatis tersimpan dalam format .csv.

\section{HASIL DAN PEMBAHASAN}

3.1 Pengolahan Data

1. Data dibawah ini merupakan data pada software unihedron device manager (UDM) yang telah disimpan pada saat perekaman ataupun pengambilan data.

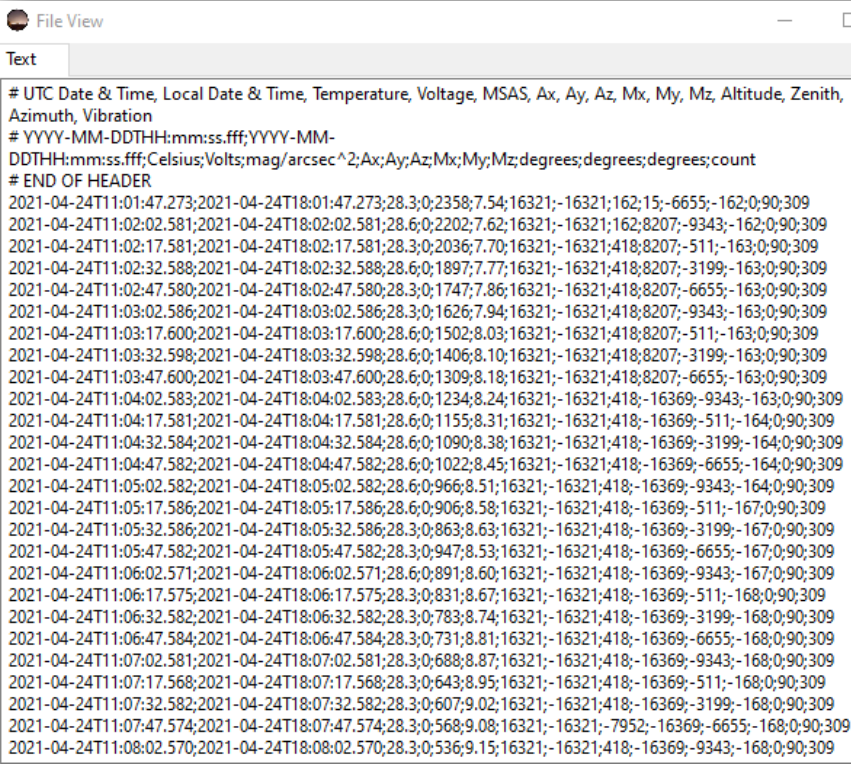

Gambar 2. Data mentah dari SQM melalui aplikasi Unihedron device manager

2. Data berikut merupakan data dari software unihedron device manager (UDM), yang perlu untuk disalin pada microsoft word.

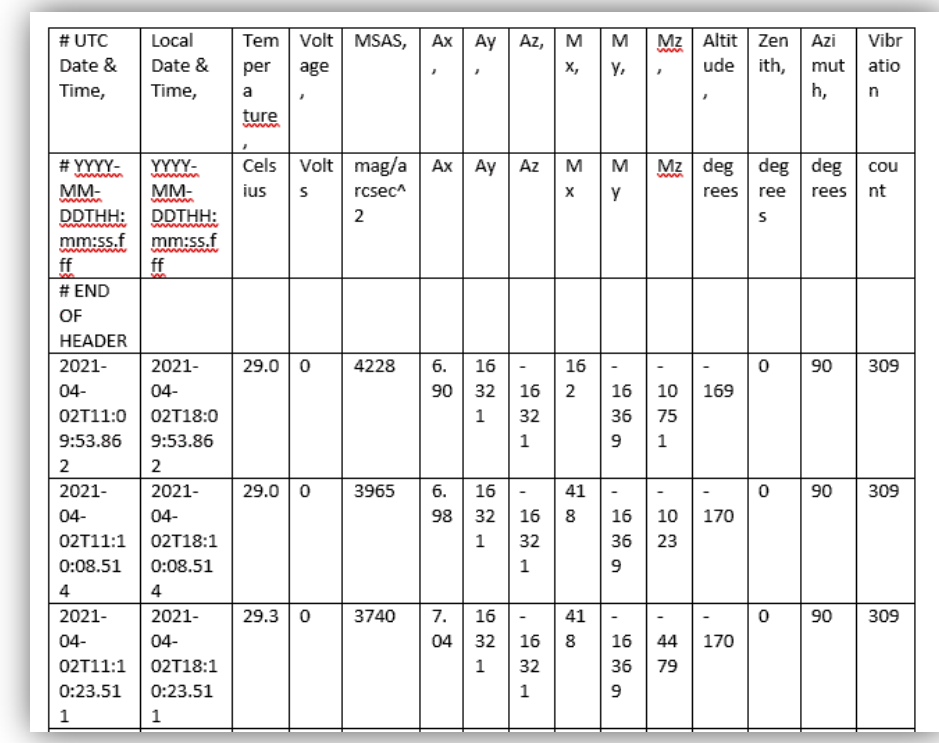

Gambar 3. Tabel data yang sudah dipindah ke dalam microsoft office word 
3. Data berikut merupakan data yang diperlukan untuk disalin kedalam microsoft office excel.

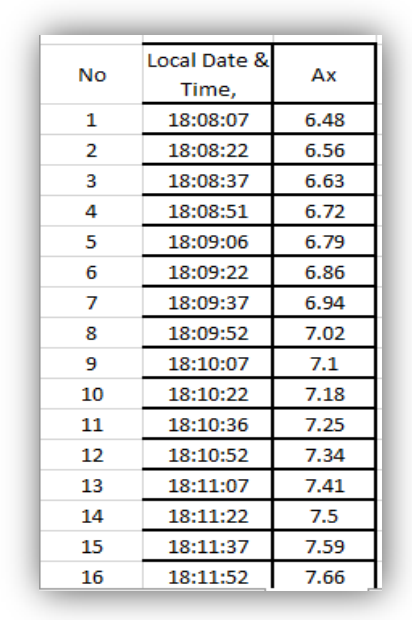

Gambar 4. Table data yang diperlukan

4. Program coding seperti pada kolom command window

5. Data berikut merupakan data yang harus dimasukan ke dalam pemrograman MATLAB sesuai dengan data yang perlukan, data yang dimaksud yaitu data No, waktu dan $A x$ (standar deviasi)

\begin{tabular}{|c|c|c|c|}
\hline \multicolumn{4}{|c|}{$\boxplus 314 \times 3$ double } \\
\hline & 1 & 2 & 3 \\
\hline 1 & 1 & 0.7530 & 5.0900 \\
\hline 2 & 2 & 0.7532 & 5.1400 \\
\hline 3 & 3 & 0.7534 & 5.2000 \\
\hline 4 & 4 & 0.7536 & 5.2500 \\
\hline 5 & 5 & 0.7537 & 5.3000 \\
\hline 6 & 6 & 0.7539 & 5.3600 \\
\hline 7 & 7 & 0.7541 & 5.4200 \\
\hline 8 & 8 & 0.7543 & 5.4700 \\
\hline 9 & 9 & 0.7544 & 5.5300 \\
\hline 10 & 10 & 0.7546 & 5.5900 \\
\hline
\end{tabular}

Gambar 5. Table data MATLAB yang sudah diinput sesuai banyaknya data

6. Berikut program persamaan polynomial 5 pada matlab, menggunakana pendekatan polynomial 5

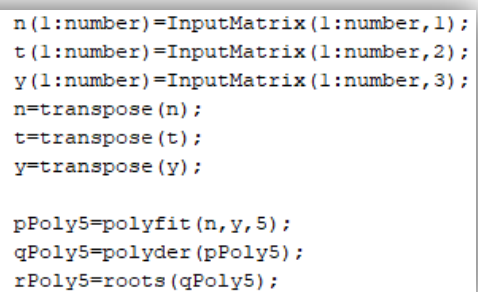

Gambar 6. Program persamaan polynomial 5 untuk program di MATLAB

7. Data berikut merupakan data yang diperoleh ketika program MATLAB dijalankan menggunakan persamaan polynomial 5.

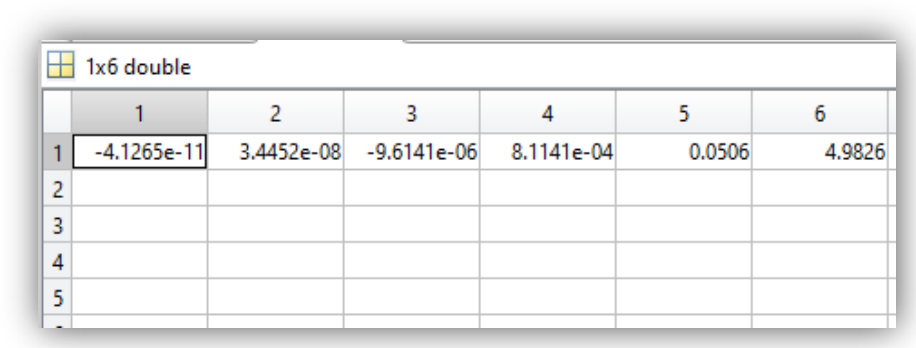

Gambar 7. Tabel persamaan yang dihasilkan dari program MATLAB 


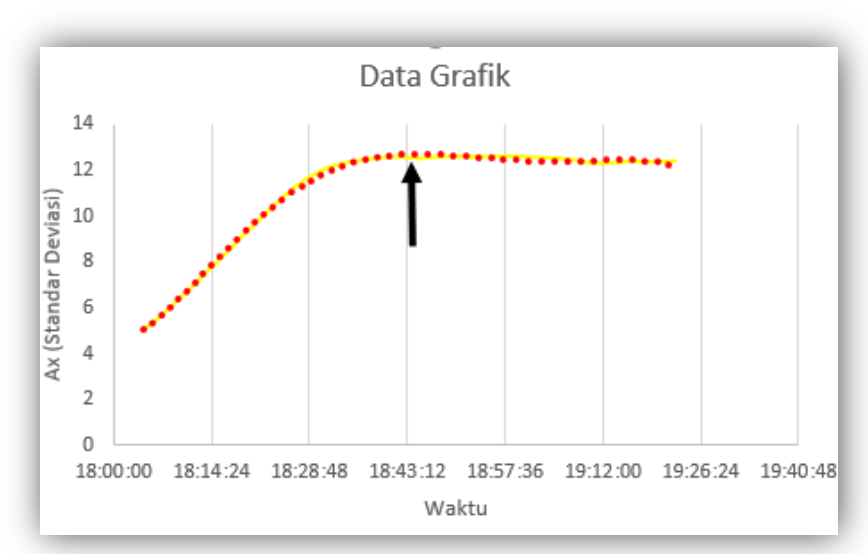

Gambar 8. Grafik tanggal 29-03-2021, data yang sudah diolah pada Microsoft office excel

Grafik diatas merupakan grafik yang sudah diolah menggunakan plot grafik pada menu Microsoft office excel dengan Ax (Standar Deviasi) terhadap waktu. Dengan menunjukan titik CutOff (potong) pada pukul 18:44:38. garis titik-titik berwarna merah sebagai garis data matematis didapat dari pendekatan polynomial 5 dan garis nyambung berwarna kuning sebagai garis data fisik (real)

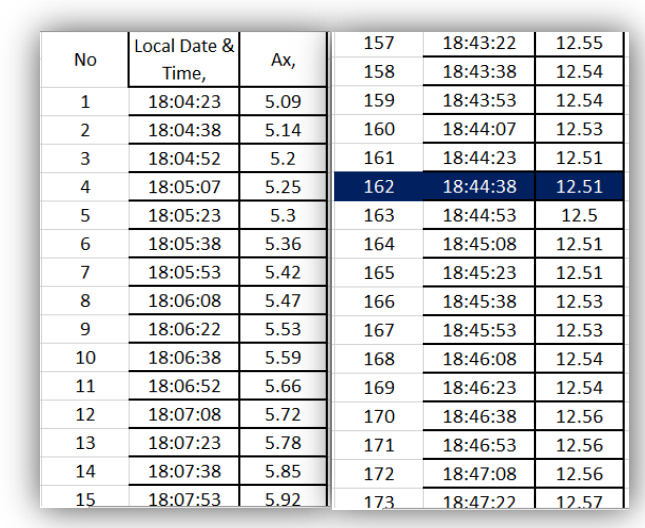

Gambar 9. Tabel data 29-03-2021, data yang sudah diolah

Data diatas merupakan data yang diperoleh dari perekaman SQM (sky quality meter) yang sudah dipindah kedadalam microsoft office excel.

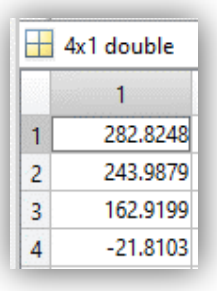

Gambar 10. Tabel data yang diolah menggunakan MATLAB

\begin{tabular}{|c|c|c|c|}
\hline & No & Waktu & \\
\hline $\mathrm{X} 1$ & 282.825 & 19:14:38 & \\
\hline $\mathrm{x} 2$ & 243.988 & 19:04:53 & \\
\hline $\mathrm{x} 3$ & 162.92 & $18: 44: 38$ & CutOff \\
\hline$X 4$ & -21.8103 & & \\
\hline
\end{tabular}

Gambar 11. Tabel data yang sudah dipindah ke Microsoft office excel

Gambar tabel diatas merupakan data yang diperoleh menggunakan program MATLAB yang mana pada gambar tabel diatas digunakan sebagai acuan dalam menentukan titik CutOff (potong) pada grafik yang sudah diplot pada microsoft office excel. 
3.2 Hasil Pengolahan data

Berikut hasil pengolahan data yang dirangkum dalam tabel 3.

Tabel 3. Hasil data waktu hilangnya syafaq yang telah melewati pengolahan data

\begin{tabular}{cccccc}
\hline No & Hari & Tanggal & Bulan & Tahun & $\begin{array}{c}\text { Waktu hilangnya } \\
\text { syafaq }\end{array}$ \\
\hline 1 & Senin & 29 & Maret & 2021 & $18: 44: 38$ \\
2 & Kamis & 1 & April & 2021 & $18: 36: 45$ \\
3 & Jum'at & 2 & April & 2021 & $18: 51: 54$ \\
4 & Sabtu & 3 & April & 2021 & $18: 38: 37$ \\
5 & Minggu & 4 & April & 2021 & $18: 35: 18$ \\
6 & Selasa & 6 & April & 2021 & $18: 43: 52$ \\
7 & Rabu & 7 & April & 2021 & $18: 42: 37$ \\
8 & Kamis & 8 & April & 2021 & $18: 46: 08$ \\
9 & Jum'at & 9 & April & 2021 & $18: 42: 51$ \\
10 & Rabu & 21 & April & 2021 & $18: 32: 59$ \\
11 & Kamis & 22 & April & 2021 & $18: 32: 45$ \\
12 & Sabtu & 24 & April & 2021 & $18: 29: 33$ \\
\hline
\end{tabular}

Data diatas merupakan data yang sudah diproses atau sudah melewati pengolahan data, dimana terdapat 12 data, yang dilakukan pengambilan selama 12 hari, dan semua data menunjukan waktu hilangnya syafaq yang berbeda-beda. Penelitian ini relevan dengan penelitian yang melakukan sebanyak 8 kali pencarian korelasi pengukuran tingkat kecerahan langit dengan menggunakan kamera smartphone dan sky quality meter berbantuan tracker (17).

\section{SIMPULAN DAN SARAN}

\subsection{Simpulan}

Berdasarkan data yang diperoleh dan sudah diproses sesuai dengan proses pengolahan data diatas, didapatkan hasil waktu hilangnya syafaq dari 12 data tersebut. Dengan hasil munculnya paling awal waktu hilangnya syafaq berdasarkan data yang didapat dan diproses yaitu pukul 18:29:33 yaitu pada tanggal 24 April, 2021 serta waktu hilangnya syafaq (cahaya mega merah) paling terakhir yaitu pukul 18:51:54 pada hari jum'at 2 April, 2021.

\subsection{Saran}

Dalam peneitian menggunakan sensor non image seperti Sky Quality Meter (SQM) masih memiliki banyak kekurangan misalnya kondisi cuaca yang kurang baik dapat mempengaruhi keakurasian Sky Quality Meter (SQM). Dan dalam menentukan titik potong (CutOff) masih dilakukan dengan cara manual yaitu melalui pengamatan melalui indera penglihatan pada data grafik yang sudah di plot, alangkah lebih baiknya jika dapat menentukan secara otomatis titik potong (CutOff) nya.

\section{DAFTAR PUSTAKA}

1. Saksono T, Anwar S. PREMATURE DOWN The Global Pattern. 1st ed. Jakarta: Suara Muhammadiyah; 2021. 1-235 p.

2. Raisal AY, Pramudya Y, Okimustava, Muchlas. The moon phases influence on the beginning of astronomical dawn determination in Yogyakarta. Int J Sci Appl Sci Conf Ser. 2017;2(1):1-7.

3. Achyani 1 YE. UJI AKURASI HISAB AWAL WAKTU SHALAT SUBUH DENGAN SKY QUALITY METER. u jmu. 2016;31-48.

4. Raihana A, Hazwan MM, Norihan K. Issues on Determination of-Accurate Fajr and Dhuha Prayer Times According to Fiqh and Astronomical Perspectives in Malaysia: A Bibliography Study. Conf Proceeding, Bali Indones Oct 13-14,2016,18 Part V. 2016;18:67580 .

5. Kyba CCC., Ruhtz T, Fischer J, Olker F. Lunar skylight polarization signal poluted by urban lightning. J Geophys Res. 2011;116:1-7. 
6. Herdiwijaya D, Matematika F, Alam P, Bandung IT. PROSIDING SKF 2016 Pengukuran Kecerahan Langit Malam arah Zenith untuk Penentuan Awal Waktu Fajar. 2016;(September):95-102.

7. Tamhid Amri. "Waktu Shalat Perspektif Syar'i." J Asy-Syari'ah. 2014;16, No. 3,:212.

8. Ismail. METODE PENENTUAN AWAL WAKTU SALAT DALAM PERSPEKTIF ILMU FALAK. 2015;14(2):218-31.

9. Ahyar M, Pramudya Y, Okimustava O. Implementasi Sistem Pengolahan Data Sky Quality Meter Berbasis Visual Basic Untuk Analisis Perubahan Tingkat Kecerahan Langit. J Kumparan Fis. 2020;3(3):239-46.

10. Farah LA. Waktu Shalat Ashar, Maghrib Dan Isya' Perspektif Hadis. Elfalaky. 2020;4(1):56-72.

11. Ahyar M, Pramudya Y, Raisal AY. Penentuan Awal Waktu Subuh Menggunakan Sky Quality. Pros SNFA (Seminar Nas Fis dan Apl 2018. 2018;184-9.

12. Herdiwijaya D. Waktu Subuh Tinjauan Pengamatan Astronomi. J Tarjih. 2017;14(1):51-64.

13. Musyafa. No Title. 2014;1.

14. Cahyono B. Penggunaan Software Matrix Laboratory (Matlab) Dalam Pembelajaran Aljabar Linier. Phenom J Pendidik MIPA. 2016;3(1):45-62.

15. Aziz A. BAB II Tinjauan Pustaka Hemoglobin. Univ Muhammadiyah Surakarta. 2013;(1969):4-27.

16. Grimsby LA, Website TF. SQM-LU-DL Operator's Manual. 2016;1197(905).

17. Fisika MP, Dahlan UA, Umbulharjo K, Istimewa D, Tracker S. SMARTPHONE DAN SKY QUALITY METER BERBANTUAN TRACKER dan CMOS ( Complementary Metal-oxide Semiconductor ). Sensor CCD bekerja Microsoft Excel . Hasil analisis dibandingkan dan dihitung nilai luminance dan. 2021;05(01):65-73. 